\title{
Web Search Considered Harmful
}

\author{
David J. Brown, Queue Advisory Board Member
}

N owadays, when you find yourself utterly disgusted by "American Idol," or any other of the latest "reality" shows on TV, you may decide, "What the heck, time to seek a slightly less horrible form of punishment: let's get on the Web."

If you're simply out for a bit of distraction, there's no end to the hours you can aimlessly fritter away with the greatest form of online adventure game yet invented. But if your desire is actually to find something you're after, the exercise may be somewhat less fulfilling. Finding something you're after is still much too hard for your average Joe (that would be me).

"Why is that?" you ask? Well, here are my top five disgruntlements with searching on the Web:

1. Can you find the "right" magic words? (a.k.a. "You can't get there from here.")

Everyone must know by now that when attempting to locate something with current search engines, the specific words you choose (and often the order of those words) are quite critical in deciding whether you get fruit or cabbage in your results. Unfortunately, it's quite difficult to know which of several perfectly plausible choices of words for your intended meaning you need to use.

Folks with a fancy computer science education will tell you that this is a "syntactic" method (one that seeks to match the particular symbols and words typed, perhaps paying attention to their order), as opposed to a "semantic" one (an attempt to seek matches for the meaning of what you've typed). Like me, I think, many will regret the apparent overwhelming emphasis on syntax over semantics in the way search engines operate upon input today.

\section{Winners of the popularity contest need not apply.} Just occasionally, you may be less unlucky than is usual and find that you've fallen upon magic words that do have some apparent relationship to the thing you were in fact after. With Google, you are then likely to be presented with a "great reward" - a prolific surfeit of offerings. ("And now, sir, which of the following 8,000 search results would you like?")

But which to choose? Given the frequently copious

\section{The top five reasons}

WHY SEARCH IS STILL

WAY TOO HARD

volume of results, modern search engines attempt to sort them into some kind of priority order. Google's search results are prioritized using a popularity algorithm. If you're tracking down the latest Britney Spears album or some other pop culture item, this may be a great help. Unfortunately, if you're after something slightly less amenable to such forceful social gravity, you'll be muttering my well-worn reprise: "Maybe that's what 'they' wanted, but it's definitely not what I'm after."

\section{Slippery slopes: Distraction, distractability, and} those advertisers' aims ("Meet Mr. Marketing") In all matters of Web search, after hurtling a few words into the search dialog box, you begin to chase hyperlinks down various of the thousands of pathways immediately offered. Once loose on the Web you'll inevitably be sidetracked by countless distractions along the way-some plausible and others designed to tempt-until you have become horribly, and hopelessly, lost.

If you're a thoroughly suggestible modern person (and happily resigned to going along with whatever "entertainment" is being dished up to you on your television tonight), you may simply surrender to these siren songs. Soon you will forget altogether your arduous quest: whence you came and whither you were going.

Remember that advertisers' dollars are the principal funding source for all the primary WWW search engine providers. These sponsors' goal is clear: they wish to (a) get your attention, (b) cause you to click through to a Web site with all those things they have for sale, and (c) ultimately "convert" that into an actual product sale. But then retail therapy is such happy anesthesia. Wouldn't you really rather be bidding on that fascinating and ohso-desirable piece of junk on eBay, anyway?

\section{Calling Ralph Nader: this vehicle has no steering} wheel! (How do you direct your search and/or narrow it down?)

But let's suppose that you're a person of steely determinaContinued on page 83 


\section{Continued from page 84}

tion. No pop-up ad or product marketing siren song can lure you away from your purpose. How then do you drive this intransigent engine?

Your only apparent resort is to try lobbing alternative collections of magic words by the fistful into the great search oracle's dialogue, to see if any greater joy might possibly be realized. Hmm, I seem to recall stories that this sort of boring mechanical and repetitive treatment is what computers were supposed to relieve us of in the first place.

\section{It must be out there, right?}

A widespread assumption is that if something exists at all, it simply must be on the Web. Regrettably, this is not true. Although it is indeed surprising how much can be found on the Web, it's a mistake to assume that everything we may wish to locate can be found there.

Many things of wide popular interest are quickly found, but what of things more particular or obscure? I challenge you to seek suppliers of parts for a 1945 M-7 Chrysler Crown marine engine. I will happily receive your instructions on how you were able to succeed, if so.

Worse still is when you do know that content you seek is on the Web, but you simply can't seem to get to it. I once navigated the PBS Web site to seek online content for a program that I'd seen. Even with such an apparently narrow search scope, and with all the seemingly appropriate keywords, I was still unable-in a half-hour's poking about-to track down the program in question.

I could go on, but what really is the point? It's just a rant, after all, and one day- "because of Moore's law," they'll probably tell you-Web search will all be perfectly blissful. But in the interim (to quote Hunter S. Thompson): "As your lawyer, I advise you to drink heavily." $Q$

\section{LOVE IT, HATE IT? LET US KNOW}

feedback@acmqueue.com or www.acmqueue.com/forums

DAVE BROWN is the commodore of the Classic Yacht Association's Northern California Fleet. Once upon a time he was a founder of Silicon Graphics and later received a Ph.D. at Cambridge University for describing a unified memory architecture for graphics workstations. After this, they gave him a job at Sun, anyway. Brown has worked on one or two big and horrible problems of software systems, including application binary compatibility in Solaris.

(c) 2004 ACM 1542-7730/04/0400 $\$ 5.00$
ACM TRANSACTIONS ON INTERNET TECHNOLOGY

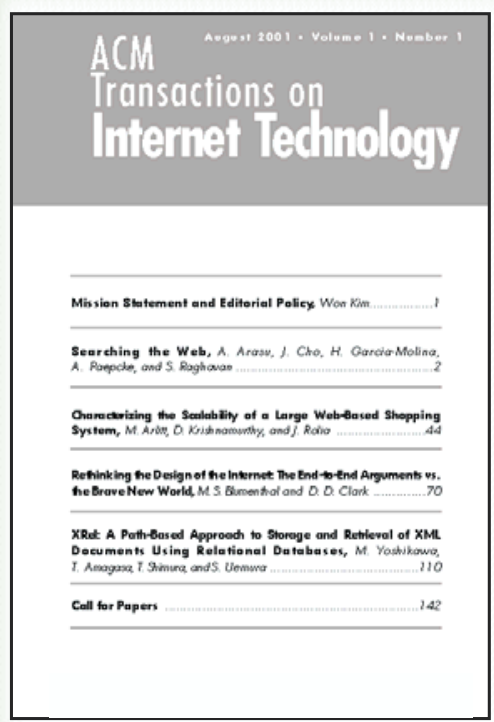

$\mathrm{AD} 22$

Transactions on Internet Technology (TOIT). This quarterly publication encompasses many disciplines in computing-including computer software engineering, middleware, database management, security, knowledge discovery and data mining, networking and distributed systems, communications, and performance and scalability-all under one roof. TOIT brings a sharper focus on the results and roles of the individual disciplines and the relationship among them. Extensive multi-disciplinary coverage is placed on the new application technologies, social issues, and public policies shaping Internet development. Subscribe Today!

\section{PRODUCT INFORMATION}

ISSN: 1533-5399

Order Code: (108)

Price: \$37 ProfessionalMember

$\$ 32$ Student Member

$\$ 150$ Non-Member

$\$ 13$ Air Service (for residents outside North America only)

Association for Computing Machinery The First Society in Computing www.acm.org

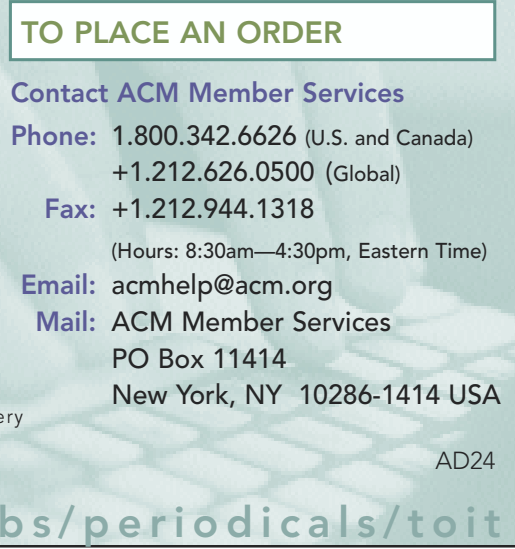

